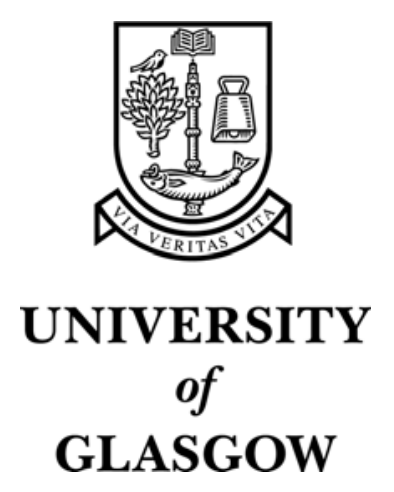

Popescu, M. and Miller, T.J.E. and McGilp, M.I. and Strappazzon, G. and Trivillin, N. and Santarossa, R. (2003) Line-start permanent-magnet motor: single-phase starting performance analysis. IEEE Transactions on Industry Applications 39(4):pp. 1021-1030.

http://eprints.gla.ac.uk/archive/2921/ 


\title{
Line-Start Permanent-Magnet Motor: Single-Phase Starting Performance Analysis
}

\author{
Mircea Popescu, Member, IEEE, T. J. E. Miller, Fellow, IEEE, Malcolm I. McGilp, Giovanni Strappazzon, \\ Nicola Trivillin, and Roberto Santarossa
}

\begin{abstract}
This paper presents a detailed quasi-steady-state approach to different torque components (average and pulsating) for a single-phase capacitor-run permanent-magnet (PM) motor. By employing average electromagnetic torque, and the expected envelope of the pulsating torque, an accurate prediction of starting torque components behavior is made. The quasi-steady-state analysis of the asynchronous performance of the single-phase capacitor-start capacitor-run PM motor is realized through a combination of symmetrical components and $d-q$ axes theory. The developed approach is valid for any $m$-phase ac motor-induction, synchronous reluctance, or synchronous PM.
\end{abstract}

Index Terms-AC motors, capacitor motors, permanent-magnet (PM) motors, starting, torque simulation.

\section{NOMENCLATURE}

$\underline{V}_{+,-}$
$\underline{V}_{d, q}, \underline{I}_{d, q}$
$R_{s}, R_{a}, R_{m}$
$X_{l s} X_{l a}, X_{l m}$
$\beta, \zeta$
$R_{r d}, R_{r q}$
$X_{l r d}, X_{l r q}$
$X_{m d}, X_{m q}$
$\underline{X}_{d \pm}, \underline{X}_{q \pm}$
$X_{d}, X_{q}$
$X_{C}, C_{r u n}$
$m, P$
$\omega, s$

Complex main supply voltage.

Complex positive/negative-sequence voltage and impedance.

Complex $d-q$ axes voltage/current components in rotor reference frame.

Stator winding resistance: equivalent/auxiliary/main.

Stator leakage reactance: equivalent/auxiliary/main.

Turns ratio (main/auxiliary) and shift electrical angle between stator windings.

Rotor resistance for $d-q$ axes.

Rotor leakage reactance for $d-q$ axes.

Magnetization reactance for $d-q$ axes.

Complex positive/negative asynchronous reactance for $d-q$ axes.

Synchronous reactance for $d-q$ axes.

Capacitive impedance/run capacitor value. Phases and poles number.

Synchronous speed $(\mathrm{rad} / \mathrm{s})$ and slip.

Paper IPCSD 03-026, presented at the 2002 Industry Applications Society Annual Meeting, Pittsburgh, PA, October 13-18, and approved for publication in the IEEE TRANSACTIONS ON INDUSTRY APPLICATIONS by the Electric Machines Committee of the IEEE Industry Applications Society. Manuscript submitted for review August 1, 2002 and released for publication April 2, 2003.

M. Popescu, T. J. E. Miller, and M. I. McGilp are with the SPEED Laboratory, University of Glasgow, Glasgow G12 8LT, U.K. (e-mail: mircea@elec.gla.ac.uk; t.miller@elec.gla.ac.uk;mal@elec.gla.ac.uk).

G. Strappazzon, N. Trivilin, and R. Santarossa are with Electrolux Compressors, 33170 Pordenone, Italy (e-mail: giovanni.strappazzon@electrolux.it: nicola.trivillin@electrolux.it; roberto1.santarossa@electrolux.it).

Digital Object Identifier 10.1109/TIA.2003.813745

\begin{abstract}
$E_{0} \quad$ No-load induced voltage.
$N_{m} \quad$ Number of turns on main stator winding.

$\phi_{m, a} \quad$ Wire diameter of the main/auxiliary winding.
\end{abstract}

\section{INTRODUCTION}

$\mathbf{P}$ ERMANENT-MAGNET motors, equipped with a cage rotor, may represent a higher efficiency alternative to induction motors. Generally defined as line-start permanent-magnet (LSPM) motors, they may be supplied from a three-phase or single-phase voltage system.

LSPM motors run synchronously so that the cage rotor losses are minimized at nominal load. The capacitor-start capacitor-run PM motor is the single-phase version of the LSPM motor. This special electric motor is suited for applications in home appliances, such as refrigerator compressors.

Beneficially, for steady-state operation, PMs considerably affect the starting capabilities of such motors. The torque oscillations, during the starting transient, are much higher than for an induction motor.

A detailed calculation of different torque components (average and pulsating) for a single-phase capacitor-run PM motor permits a correct estimation of motor performance. It extends the existing analysis made for a single-phase unsymmetrical [1], [4] or three-phase symmetrical [2], [3] PM motor. The analysis focuses on a single-phase capacitor-start capacitor-run $50-\mathrm{Hz}$ two-pole motor with concentric windings. The rotor consists of an aluminum rotor cage, with interior ferrite magnets (see Fig. 1).

\section{Modeling the CAGE TorqueS}

The traditional way to study the asynchronous starting process of an LSPM motor is to subdivide it into two different regions [3]: 1) the run-up response up to the "rated induction motor operating point" and 2) the transition zone from that point to synchronism.

The accelerating torque is given by the cage torque minus the magnet braking torque and load torque.

The unbalanced stator voltage for the case of capacitor-start and/or capacitor-run motors affects both the starting and synchronous operation. For a detailed analysis of the torque behavior of the LSPM motor, a suitable combination of the symmetrical components and $d-q$ axes theory [1], [3] will give accurate results. 


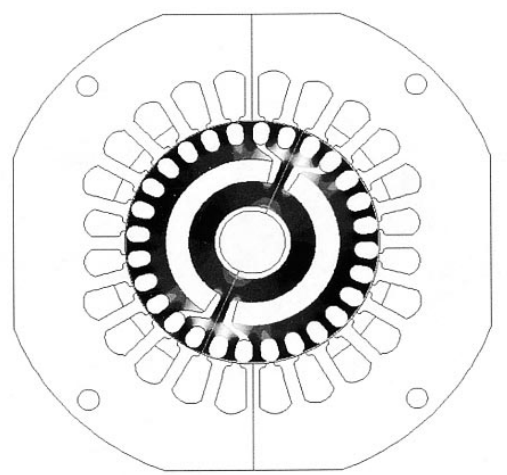

Fig. 1. Cross section of analyzed motor.

An unbalanced supply voltage system can be decomposed using symmetrical components as

$$
\left\{\begin{array}{l}
\underline{V}_{d}=\frac{1}{\sqrt{2}} \cdot\left(\underline{V}_{+}+\underline{V}_{-}\right)=\frac{1}{\sqrt{2}} \cdot\left(\underline{V}_{d+}+\underline{V}_{d-}\right) \\
\underline{V}_{q}=\frac{1}{\sqrt{2}} \cdot\left(-j \underline{V}_{+}+j \underline{V}_{-}\right)=\frac{1}{\sqrt{2}} \cdot\left(\underline{V}_{q+}+\underline{V}_{q-}\right) .
\end{array}\right.
$$

The positive-sequence $V_{+}$will induce currents in the cage rotor of the LSPM motor. The currents frequency will be $s f$. In a similar way, the negative-sequence $V_{-}$will induce currents in the cage rotor, with $(2-s) f$ frequency. In double revolving field theory, currents with $s f$ frequency determine the forward field, and the $(2-s) f$ frequency currents determine the backward field. Thus, the initial unbalanced LSPM motor is equivalent to two stator-balanced motors. Each of these fictitious motors is characterized by an asymmetrical rotor configuration, due to the cage and saliency. Using the $d-q$ axes fixed on the rotor frame, we can write the following stator voltage equations for the positive-sequence motor:

$$
\begin{aligned}
& \underline{V}_{d+}=\underline{V}_{+}=R_{s} \underline{I}_{d+}+j s \omega \underline{\psi}_{d+}-(1-s) \omega \underline{\psi}_{q+} \\
& \underline{V}_{q+}=-j \underline{V}_{+}=R_{s} \underline{I}_{q+}+j s \omega \underline{\psi}_{q+}+(1-s) \omega \underline{\psi}_{d+}
\end{aligned}
$$

and for the negative-sequence motor

$$
\begin{aligned}
& \underline{V}_{d-}=\underline{V}_{-}=R_{s} \underline{I}_{d-}+j(2-s) \omega \underline{\psi}_{d-}-(1-s) \omega \underline{\psi}_{q-} \\
& \underline{V}_{q-}=j \underline{V}_{-}=R_{s} \underline{I}_{q-}+j(2-s) \omega \underline{\psi}_{q-}+(1-s) \omega \underline{\psi}_{d-}
\end{aligned}
$$

For the flux linkage components we will use the notations [3]

$$
\begin{aligned}
& \omega \underline{\psi}_{d \pm}=\underline{X}_{d \pm}(j s) \underline{I}_{d \pm}=-j \underline{Z}_{d \pm} \underline{I}_{d \pm} \\
& \omega \underline{\psi}_{q \pm}=\underline{X}_{q \pm}(j s) \underline{I}_{q \pm}=-j \underline{Z}_{q \pm} \underline{I}_{q \pm} .
\end{aligned}
$$

Introducing (4) in (2) and (3), and solving the equation systems, we obtain the equivalent relations for $d-q$ axes currents positive sequence

$$
\begin{aligned}
& \underline{I}_{d+}=\frac{j \underline{V}_{+}}{D_{+}} \cdot\left[-R_{s}+j(2 s-1) \underline{X}_{q+}\right] \\
& \underline{I}_{q+}=-\frac{V_{+}}{D_{+}} \cdot\left[-R_{s}+j(2 s-1) \underline{X}_{d+}\right]
\end{aligned}
$$

negative sequence

$$
\begin{aligned}
& \underline{I}_{d-}=\frac{\underline{V}_{-}}{D_{-}} \cdot\left[R_{s}+j(3-2 s) \underline{X}_{d-}\right] \\
& \underline{I}_{q-}=\frac{j \underline{V}-}{D_{-}} \cdot\left[R_{s}+j(3-2 s) \underline{X}_{q-}\right]
\end{aligned}
$$

where

$$
\begin{aligned}
D_{+}= & R_{s}^{2}+(1-2 s) \underline{X}_{d+} \underline{X}_{q+}+j s R_{s}\left(\underline{X}_{d+}+\underline{X}_{q+}\right) \\
D_{-}= & R_{s}^{2}+(2 s-3) \underline{X}_{d-} \underline{X}_{q-} \\
& +j(2-s) R_{s}\left(\underline{X}_{d-}+\underline{X}_{q-}\right) .
\end{aligned}
$$

For the single-phase motor, with an unsymmetrical stator winding, by using the relations in [1], we can deduce (the stator windings are assumed to have the same copper weight, i.e., $\left.R_{s}=R_{m}=\beta^{2} R_{a}, X_{l s}=X_{l m}=\beta^{2} X_{l a}, \phi_{a}=\beta^{1 / 2} \phi_{m}\right)$

$$
\begin{aligned}
& \underline{V}_{+}=\underline{V}_{m} \cdot \frac{\sqrt{2} \sin \zeta}{\beta} \cdot \frac{h \beta+j \underline{a}_{2}}{\underline{a}_{1}+\underline{a}_{2}} \\
& \underline{V}_{-}=\underline{V}_{m} \cdot \frac{\sqrt{2} \sin \zeta}{\beta} \cdot \frac{h \beta-j \underline{a}_{1}}{\underline{a}_{1}+\underline{a}_{2}}
\end{aligned}
$$

where

$$
\begin{aligned}
h & =\frac{1+\cos (\zeta)}{\sin (\zeta)} \\
\underline{a}_{1} & =1-\frac{j X_{C}}{\underline{Z}_{+}} \cdot\left(1+\frac{j}{\beta \cdot \tan (\zeta)}\right) \\
\underline{a}_{1} & =1-\frac{j X_{C}}{\underline{Z}_{-}} \cdot\left(1-\frac{j}{\beta \cdot \tan (\zeta)}\right) .
\end{aligned}
$$

The presence of the capacitive impedance connected in series with the auxiliary winding requires a special usage of the symmetrical components. A suitable option is to include the capacitor voltage in the positive- and negative-sequence voltages. The positive- and negative-sequence impedances are approximated using the average of the apparent (variable with slip $s$ ) $d$ and $q$-axes impedances

$$
\begin{aligned}
& \underline{Z}_{+}=R_{s}+j X_{l s}+\frac{1}{2} \cdot\left[\begin{array}{c}
\frac{j X_{m d} \cdot\left(\frac{R_{r d}}{s}+j X_{l r d}\right)}{\frac{R_{r d}}{s}+j \cdot\left(X_{m d}+X_{l r d}\right)} \\
j X_{m q} \cdot\left(\frac{R_{r q}}{s}+j X_{l r q}\right) \\
+\frac{R_{r q}}{s}+j \cdot\left(X_{m q}+X_{l r q}\right)
\end{array}\right] \\
& \underline{Z}_{-}=R_{s}+j X_{l s}+\frac{1}{2} \cdot\left[\begin{array}{c}
j X_{m d} \cdot\left(\frac{R_{r d}}{2-s}+j X_{l r d}\right) \\
\frac{R_{r d}}{2-s}+j \cdot\left(X_{m d}+X_{l r d}\right) \\
+\frac{j X_{m q} \cdot\left(\frac{R_{r q}}{2-s}+j X_{l r q}\right)}{\frac{R_{r q}}{2-s}+j \cdot\left(X_{m q}+X_{l r q}\right)}
\end{array}\right] .
\end{aligned}
$$




\section{Cage Torque Components}

The following relations compute the average cage torque components (positive and negative sequence) valid for an $m$-phase ac motor with unbalanced stator voltage:

$$
\begin{gathered}
T_{(\mathrm{avg})+}=\frac{m}{2} \cdot \frac{P}{2} \cdot \operatorname{Re}\left\{\left(\underline{\psi}_{q+}\right)^{*} \underline{I}_{d+}-\left(\underline{\psi}_{d+}\right)^{*} \underline{I}_{q+}\right\} \\
T_{(\mathrm{avg})-}=\frac{m}{2} \cdot \frac{P}{2} \cdot \operatorname{Re}\left\{\left(\underline{\psi}_{q-}\right)^{*} \underline{I}_{d-}-\left(\underline{\psi}_{d-}\right)^{*} \underline{I}_{q-}\right\} .
\end{gathered}
$$

Each of these two average torque components can be further divided into another two components. In this way, the analysis of the starting capabilities of the LSPM motor can be accomplished for a wider range of frequencies. The electromagnetic asymmetry of the rotor leads to the following sequence components, as seen from the rotor reference frame.

1) For the positive-sequence frequency $(s f)$, the rotor field is decomposed into two components: forward component, which rotates versus the rotor with $s n_{1}$ speed; backward component, which rotates versus the rotor with $\left(-s n_{1}\right)$ speed.

These two revolving fields rotate versus the stator with the following speeds:

a) forward component

$$
s n_{1}+n=s n_{1}+(1-s) n_{1}=n_{1}
$$

b) backward component

$$
-s n_{1}+n=-s n_{1}+(1-s) n_{1}=(1-2 s) n_{1} .
$$

2) For the negative-sequence frequency $(2-s) f$, the rotor field is decomposed into two components: forward component, which rotates versus the rotor with $(2-s) n_{1}$ speed; backward component, which rotates versus the rotor with $(s-2) n_{1}$ speed.

These two revolving fields rotate versus the stator with the following speeds:

a) forward component

$$
(2-s) n_{1}+n=(2-s) n_{1}+(1-s) n_{1}=(3-2 s) n_{1}
$$

b) backward component

$$
(s-2) n_{1}+n=(s-2) n_{1}+(1-s) n_{1}=-n_{1} .
$$

The stator voltage equations (2) and (3) can be rewritten as follows for the positive-sequence components:

$$
\begin{aligned}
\underline{V}_{+}= & R_{s} \underline{I}_{f+}+\frac{1}{2} \cdot\left(\underline{Z}_{d+}+\underline{Z}_{q+}\right) \underline{I}_{f+}+\frac{1}{2} \\
& \cdot\left(\underline{Z}_{d+}-\underline{Z}_{q+}\right) \underline{I}_{b+} \\
0= & \frac{R_{s}}{2 s-1} \underline{I}_{b+}+\frac{1}{2} \cdot\left(\underline{Z}_{d+}-\underline{Z}_{q+}\right) \underline{I}_{f+}+\frac{1}{2} \\
& \cdot\left(\underline{Z}_{d+}+\underline{Z}_{q+}\right) \underline{I}_{b+}
\end{aligned}
$$

and, respectively, for the negative-sequence component

$$
\begin{aligned}
0= & \frac{R_{s}}{3-2 s} \underline{I}_{f-}+\frac{1}{2} \cdot\left(\underline{Z}_{d-}+\underline{Z}_{q-}\right) \underline{I}_{f-}+\frac{1}{2} \\
& \cdot\left(\underline{Z}_{d-}-\underline{Z}_{q-}\right) \underline{I}_{b-} \\
-\underline{V}_{-}= & R_{s} \underline{I}_{b-}+\frac{1}{2} \cdot\left(\underline{Z}_{d-}-\underline{Z}_{q-}\right) \underline{I}_{f-}+\frac{1}{2} \\
& \cdot\left(\underline{Z}_{d-}+\underline{Z}_{q-}\right) \underline{I}_{b-}
\end{aligned}
$$

where the indexes $f$ and $b$ stand for forward and backward components.

After algebraic manipulations, we obtain the forward and backward current expressions as

$$
\begin{aligned}
& \underline{I}_{f+}=\underline{V}_{+} \frac{\underline{Z}_{d b+}+\underline{Z}_{q b+}}{\underline{Z}_{d f+} \underline{Z}_{q b+}+\underline{Z}_{d b+} \underline{Z}_{q f+}} \\
& \underline{I}_{b+}=-\underline{V}_{+} \frac{\underline{Z}_{d f+}-\underline{Z}_{q f+}}{\underline{Z}_{d f+} \underline{Z}_{q b+}+\underline{Z}_{d b+} \underline{Z}_{q f+}} \\
& \underline{I}_{f-}=-\underline{V}_{-} \frac{\underline{Z}_{d b-}-\underline{Z}_{q b-}}{\underline{Z}_{d f-} \underline{Z}_{q b-}+\underline{Z}_{d b-} \underline{Z}_{q f-}} \\
& \underline{I}_{b-}=\underline{V}_{-} \frac{\underline{Z}_{d f-}+\underline{Z}_{q f-}}{\underline{Z}_{d f-} \underline{Z}_{q b-}+\underline{Z}_{d b-} \underline{Z}_{q f-}}
\end{aligned}
$$

where

$$
\left\{\begin{array}{l}
\underline{Z}_{d \pm}=j \underline{X}_{d \pm}=\underline{Z}_{m d \pm}+j X_{l s} \\
\underline{Z}_{q \pm}=j \underline{X}_{q \pm}=\underline{Z}_{m q \pm}+j X_{l s}
\end{array}\right.
$$

$$
\begin{aligned}
& \left\{\begin{array}{l}
\underline{Z}_{d f+}=\underline{Z}_{m d+}+R_{s}+j X_{l s} \\
\underline{Z}_{q f+}=\underline{Z}_{m q+}+R_{s}+j X_{l s} \\
\underline{Z}_{d b+}=\underline{Z}_{m d+}+\frac{R_{s}}{2 s-1}+j X_{l s} \\
\underline{Z}_{q b+}=\underline{Z}_{m q+}+\frac{R_{s}}{2 s-1}+j X_{l s}
\end{array}\right. \\
& \left\{\begin{array}{l}
\underline{Z}_{d f-}=\underline{Z}_{m d-}+\frac{R_{s}}{2 s-3}+j X_{l s} \\
\underline{Z}_{q f-}=\underline{Z}_{m q-}+\frac{R_{s}}{2 s-3}+j X_{l s} \\
\underline{Z}_{d b-}=\underline{Z}_{m d-}-R_{s}+j X_{l s} \\
\underline{Z}_{q b-}=\underline{Z}_{m q-}-R_{s}+j X_{l s} .
\end{array}\right.
\end{aligned}
$$

The following relations compute the average cage torque components (positive and negative sequences split in forward and backward components) valid for an $m$-phase ac motor with unbalanced stator voltage:

$$
\begin{aligned}
& T_{(\mathrm{avg}) f+}=\frac{m P}{2 \omega} \cdot R_{e+} \cdot\left|\underline{I}_{f+}\right|^{2} \\
& T_{(\mathrm{avg}) b+}=\frac{m P}{2 \omega} \cdot \frac{R_{s}}{2 s-1} \cdot\left|\underline{I}_{b+}\right|^{2} \\
& T_{(\mathrm{avg}) f-}=\frac{m P}{2 \omega} \cdot \frac{R_{s}}{2 s-3} \cdot\left|\underline{I}_{f-}\right|^{2} \\
& T_{(\mathrm{avg}) b-}=\frac{m P}{2 \omega} \cdot R_{e-} \cdot\left|\underline{I}_{b-}\right|^{2}
\end{aligned}
$$


where $R_{e(+,-)}$ represent the equivalent resistances computed with the following relations:

$$
\begin{aligned}
& R_{e+}=\operatorname{Re}\left\{\frac{1}{2}\left[\left(\underline{Z}_{m d+}+\underline{Z}_{m q+}\right)-\frac{\left(\underline{Z}_{m d+}-\underline{Z}_{m q+}\right)^{2}}{\underline{Z}_{d b+}+\underline{Z}_{q b+}}\right]\right\} \\
& R_{e-}=\operatorname{Re}\left\{\frac{1}{2}\left[-\left(\underline{Z}_{m d-}+\underline{Z}_{m q-}\right)+\frac{\left(\underline{Z}_{m d-}-\underline{Z}_{m q-}\right)^{2}}{\underline{Z}_{d f-}+\underline{Z}_{q f-}}\right]\right\}
\end{aligned}
$$

while the equivalent magnetization impedances are

$$
\begin{aligned}
\underline{Z}_{m d+} & =\frac{1}{\frac{1}{j X_{m d}}+\frac{s}{R_{r d}+j \cdot s X_{l r d}}} \\
\underline{Z}_{m q+} & =\frac{1}{\frac{1}{j X_{m q}}+\frac{s}{R_{r q}+j \cdot s X_{l r q}}} \\
\underline{Z}_{m d-} & =\frac{1}{\frac{1}{j X_{m d}}+\frac{(2-s)}{R_{r d}+j \cdot(2-s) X_{l r d}}} \\
\underline{Z}_{m q-} & =\frac{1}{\frac{1}{j X_{m q}}+\frac{(2-s)}{R_{r q}+j \cdot(2-s) X_{l r q}}} .
\end{aligned}
$$

The total average cage torque may be computed as

$$
\begin{aligned}
T_{(\mathrm{avg})} & =T_{(\mathrm{avg})+}+T_{(\mathrm{avg})-} \\
& =T_{(\mathrm{avg}) f+}+T_{(\mathrm{avg}) b+}+T_{(\mathrm{avg}) f-}+T_{(\mathrm{avg}) b-} .
\end{aligned}
$$

\section{Modeling THE Magnet BRaking TORQUe}

A complete $d-q$ axes analysis of the magnet braking torque for a three-phase symmetrical LSPM motor is given in [2].

Expressions for determining the currents and the flux linkages due to the magnets, and the magnet braking torque, are determined accordingly for the unsymmetrical single-phase LSPM motor

$$
\begin{aligned}
& \left\{\begin{array}{l}
I_{d m}=\frac{-(1-s)^{2} \cdot\left(X_{q}-X_{C}\right)}{R_{s}^{2}+X_{d}\left(X_{q}-X_{C}\right)(1-s)^{2}} \cdot E_{0} \\
I_{q m}=\frac{-(1-s) R_{s}}{R_{s}^{2}+X_{d}\left(X_{q}-X_{C}\right)(1-s)^{2}} \cdot E_{0}
\end{array}\right. \\
& \left\{\begin{array}{l}
\psi_{d m}=\frac{X_{d} I_{d m}+E_{0}}{\omega} \\
\psi_{q m}=\frac{\left(X_{q}-X_{C}\right) \cdot I_{q m}}{\omega}
\end{array}\right. \\
& T_{m}=\frac{P}{2} \cdot \sin (\zeta)\left[\beta \cdot \psi_{d m} I_{q m}-\frac{1}{\beta} \cdot \psi_{q m} I_{d m}\right] .
\end{aligned}
$$

Expression (34) shows the possibility of decreasing the magnet braking torque when the stator windings of the single-phase LSPM motor are electrically nonorthogonal.

However, a more accurate analytical model may be needed for the magnet braking torque in the case of the one-phase unbalanced LSPM motor, when the stator windings weight is not equal. The induced magnetic fluxes by the PM in both windings (main and auxiliary) depend on the rotor speed. Their amplitude is proportional to the effective ampere-turns in the respec-
TABLE I

HARMonics of THE PUlsating ToRQue (Rotor REFERENCE Frame)

\begin{tabular}{llll}
\hline \hline \multicolumn{1}{c}{ Frequency } & \multicolumn{1}{c}{$\begin{array}{c}\text { Positive seq. } \\
\text { components }\end{array}$} & \multicolumn{1}{c}{$s f$} & \multicolumn{1}{c}{ Negative seq. } \\
$(2-s) f$ & \multicolumn{1}{c}{ Magnet } \\
Positive seq. $s f$ & $2 s f$ & $2 f,(2-2 s) f$ & 0 \\
Negative seq. $(2-s) f f$ & $2 f,(2-2 s) f$ & $(4-2 s) f$ & $(2-s) f$ \\
& & & \\
Magnet 0 & $s f$ & $(2-s) f$ & 0 \\
\hline
\end{tabular}

tive winding. The magnet braking torque is given by the interaction between the stator currents and the induced magnetic fluxes by the PM in these windings. As the stator currents amplitudes and phase angles are different (i.e., unbalanced system), this explains why the exact analytical expression for this torque component is impossible to deduce in $d-q$ axes theory, without the assumption in Section II. A literature survey [6], [7], [9] shows that even using the complicated finite-element (FE) technique, the magnet braking torque prediction has not yet been realized.

\section{Modeling the Pulsating Torques}

Analysis of the LSPM motor is made using the rotor reference frame and the rotor current components correspond to two induced currents and the equivalent current that is determined by the PM. Their frequencies are: 1) $s f$ harmonic, represented by the positive cage sequence; 2$)(2-s) f$ harmonic, represented by the negative cage sequence; and 3) 0 , represented by the PM equivalent current.

In the rotor reference frame the asynchronous operation as an induction motor and the influence of the PMs determine the stator current components. Their frequencies are: 1) the fundamental $(f)$ represented by the positive forward and negative backward sequence cage component; 2) $(1-2 s) f$ harmonic, represented by the positive backward cage sequence; 3) $(3-2 s) f$ harmonic, represented by the negative forward cage component; and 4) $(1-s) f$ harmonic, represented by the induced stator currents due to the magnet rotation. These harmonics interact and determine several pulsating torques.

The interaction between the rotor current components determines four cage pulsating torque components and two permanent pulsating torque components [2]. Table I shows the resultant frequencies of these pulsating torques.

We may classify the amplitude (zero to peak) of the pulsating torques according to their main cause in reluctance, unbalanced stator, and PM (excitation) pulsating torque components as follows:

reluctance pulsating torques

$$
\begin{aligned}
& T_{(\text {puls)(2sf) }} \\
& \quad=\frac{m}{2} \cdot \frac{P}{2} \cdot A b s\left\{\left(\underline{\psi}_{q+}\right) \underline{I}_{d+}-\left(\underline{\psi}_{d+}\right) \underline{I}_{q+}\right\} \\
& T_{(\text {puls)(4-2s)f }} \\
& \quad=\frac{m}{2} \cdot \frac{P}{2} \cdot \operatorname{Abs}\left\{\left(\underline{\psi}_{q-}\right) \underline{I}_{d-}-\left(\underline{\psi}_{d-}\right) \underline{I}_{q-}\right\}
\end{aligned}
$$

unbalanced stator pulsating torques

$$
\begin{aligned}
& T_{(\mathrm{puls})(2 f)} \\
& \quad=\frac{m}{2} \cdot \frac{P}{2} \cdot A b s\left\{\left(\underline{\psi}_{q+}\right) \underline{I}_{d-}-\left(\underline{\psi}_{d+}\right) \underline{I}_{q-}\right\}
\end{aligned}
$$


TABLE II

STATOR WINDING DATA

\begin{tabular}{|c|c|c|c|c|}
\hline \multirow{2}{*}{$\begin{array}{l}\text { Motor } \\
\text { Type }\end{array}$} & \multicolumn{4}{|c|}{ Winding parameters } \\
\hline & $\mathrm{N}_{\mathrm{m}}$ [p.u.] & $\beta$ & $\phi_{m} / \phi_{\mathrm{a}}$ & $\zeta\left[\right.$ elec $^{\circ}$ ] \\
\hline Motor A & 1.46 & 1.42 & 1.22 & 90 \\
\hline Motor B & 1.14 & 1.42 & 1.3 & 90 \\
\hline Motor C & 1 & 1 & 1 & 90 \\
\hline Motor D & 0.87 & 0.70 & 0.76 & 90 \\
\hline
\end{tabular}

$$
\begin{aligned}
& T_{(\mathrm{puls})(2-2 s) f} \\
& \quad=\frac{m}{2} \cdot \frac{P}{2} \cdot A b s\left\{\left(\underline{\psi}_{q_{-}}\right) \underline{I}_{+}-\left(\underline{\psi}_{d_{-}}\right) \underline{I}_{q+}\right\}
\end{aligned}
$$

\section{PM (excitation) pulsating torques}

$$
\begin{aligned}
& T_{(\mathrm{puls})(s f)} \\
& =m \cdot \frac{P}{2} \cdot A b s\left\{\begin{array}{l}
\left.\left[\underline{\psi}_{q+}\right) I_{d m}+\left(\psi_{q m}\right) \underline{I}_{d+}\right] \\
-\left[\left(\underline{\psi}_{d+}\right) I_{q m}+\left(\psi_{d m}\right) \underline{I}_{q+}\right]
\end{array}\right\} \\
& T_{(\mathrm{puls})(2-s) f} \\
& =m \cdot \frac{P}{2} \cdot A b s\left\{\begin{array}{l}
{\left[\begin{array}{l}
\left.\left(\underline{\psi}_{q-}\right) I_{d m}+\left(\psi_{q m}\right) \underline{I}_{d-}\right] \\
-\left[\left(\underline{\psi}_{d-}\right) I_{q m}+\left(\psi_{d m}\right) \underline{I}_{q-}\right]
\end{array}\right\} .}
\end{array}\right.
\end{aligned}
$$

Note that while the reluctance and excitation pulsating torques total effect is given by their sum, the unbalanced stator pulsating torque effect is given by their difference.

\section{EXPERIMENTAL AND SIMULATION RESULTS}

The experiments were performed on four motor types, equipped with identical rotor, and stator lamination, but with different stator windings. The stator winding data are presented in Table II. Note that the assumption made in Section II (stator windings with equal copper weight), is not valid for all tested motors. Only motors C and D were wound with the same copper weight in both stator windings. This way it is possible to observe the influence of this assumption on the simulations, when compared to the experimental data.

During starting, the accelerating torque of the LSPM motor is the average cage torque minus the magnet braking torque and the load torque. The average cage torque is developed by "induction motor action," except that the saliency and the unbalanced stator voltages complicate the analysis and may compromise the performance.

The magnet braking torque is produced by the fact that the magnet flux generates currents in the stator windings, and is associated with the loss in the stator circuit resistance. The variation of this torque with speed follows a pattern similar to that in the induction motor, but the per-unit speed takes the place of the slip.

The magnet braking torque should not be confused with the synchronous "alignment" torque that arises at synchronous speed, even though the magnet braking torque is still present at synchronous speed and, therefore, diminishes the output and the efficiency. The magnet alignment torque has a nonzero

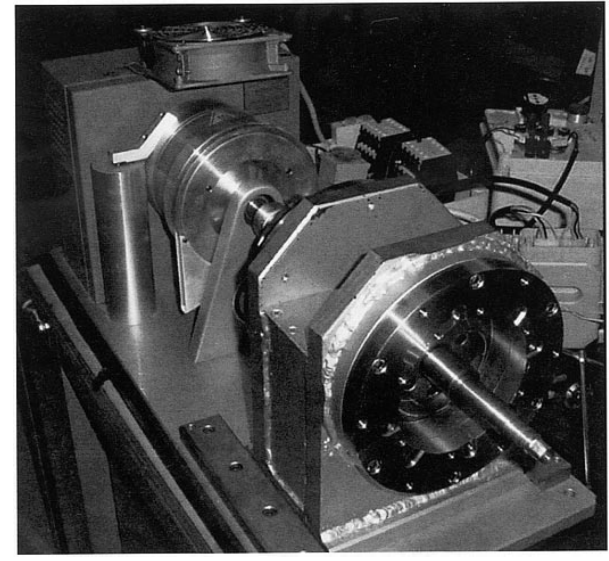

Fig. 2. Test stand settings.

average value (i.e., averaged over one revolution or electrical cycle) only at synchronous speed. At all other speeds it contributes an oscillatory component of torque that is very evident in Figs. 11-13. The same is true of the reluctance torque. As the rotor approaches synchronous speed, the screening effect of the cage becomes less, and as the slip is very small, the oscillatory synchronous torques (alignment and reluctance) cause large variations in speed that may impair the ability to synchronize large-inertia loads.

There are presented the simulation results for the case when two capacitors are used, $23 \mu \mathrm{F}$ for starting operation and $3 \mu \mathrm{F}$ for running operation (above 80\%-90\% of synchronous speed), for all the analyzed LSPM motor types. The start capacitor was selected as an average between the optimum values for each tested motor considering maximum torque/current at starting operation. The run capacitor was selected as an average between the optimum values for each of the analyzed motors considering maximum efficiency at synchronous operation and nominal load.

Note that these values do not correspond to the optimum values of any of the analyzed motors. A tradeoff has to be made depending on the application: lower starting torque and efficiency at synchronous operation, but increased load torque and synchronization capability (motor B); higher starting torque and efficiency at synchronous operation, but decreased load torque and synchronization capability (motors A and C); and higher starting and load torque and synchronization capability, but lower efficiency at synchronous operation and higher magnetic noise, i.e., pulsating torques (motor D). This paper focuses on the torque behavior during starting operation. Therefore the measurements and computations for the synchronous operation are not included.

The magnet braking torque exhibits a maximum in a range from $0.25 \mathrm{~N} \cdot \mathrm{m}$ (Motor B) to $0.65 \mathrm{~N} \cdot \mathrm{m}$ (Motor D). The cage torque in all the cases overcomes the magnet braking torque.

The test stand settings are illustrated in Fig. 2. Figs. 3-6 illustrate the experimental quasi-steady-state torque variation versus speed during no-load operation for a line-start PM motor, supplied with an unbalanced stator voltage system, with a capacitor-start value of $23 \mu \mathrm{F}$. Tested machines were driven as motors or generators using a hysteresis brake or a dc-load motor. Consequently, the LSPM motor shaft torque was measured as a 


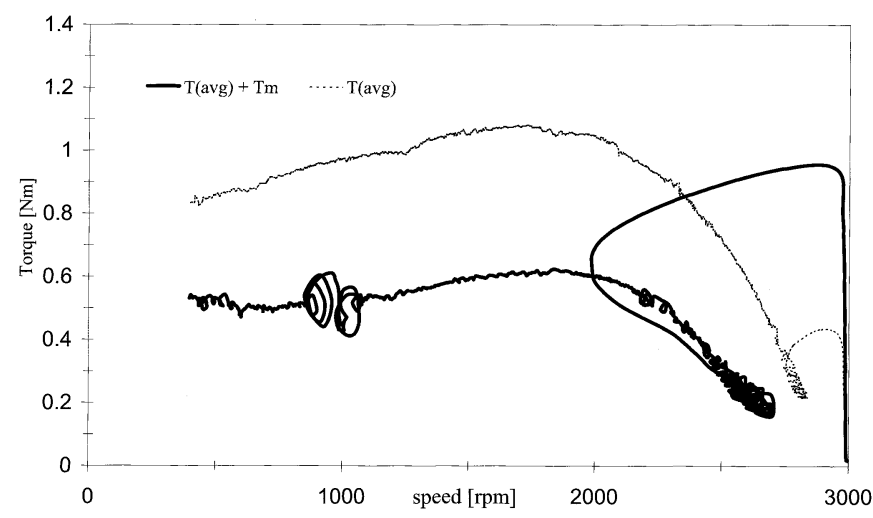

Fig. 3. Experimental torque variation versus speed during no-load operation, Motor A.

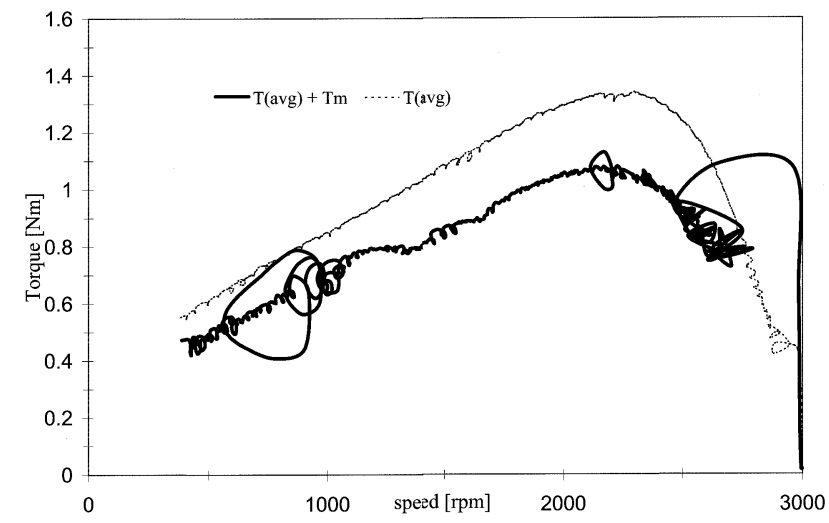

Fig. 4. Experimental torque variation versus speed during no-load operation, Motor B.

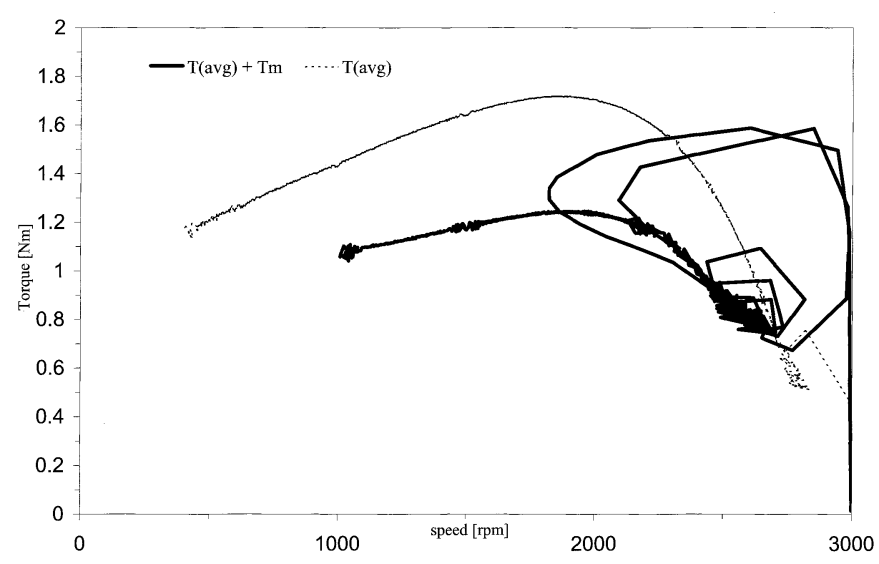

Fig. 5. Experimental torque variation versus speed during no-load operation, Motor C.

braking torque. The experiments required the usage of two rotors for every tested motor: one equipped with the cage rotor but without magnets and one equipped with cage rotor and with magnets inserted. The higher torque values (dotted line) have been measured when the rotor is without PMs $\left(T_{(\mathrm{avg})}\right)$. The lower torque values (solid line) represent the experimental data for the actual motor equipped with PMs $\left(T_{(\text {avg })}+T_{m}\right)$. The experiments were intended to study the torque behavior during

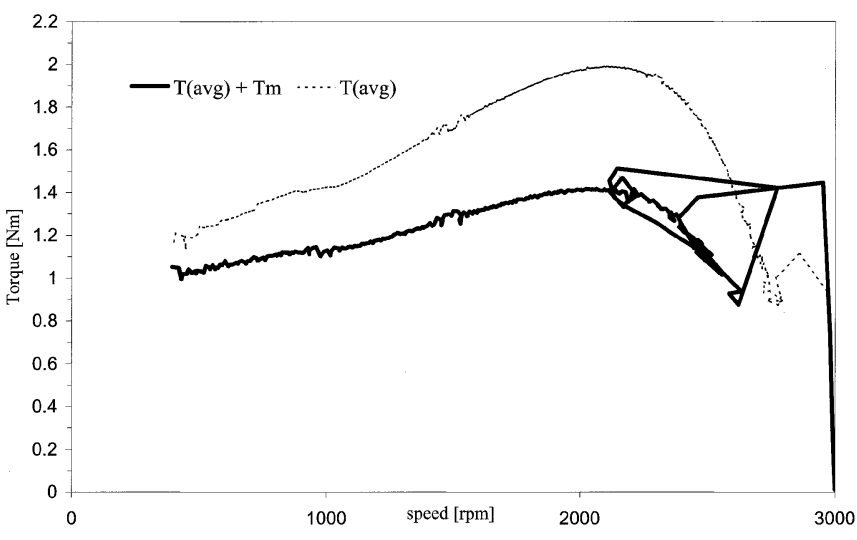

Fig. 6. Experimental torque variation versus speed during no-load operation, Motor D.

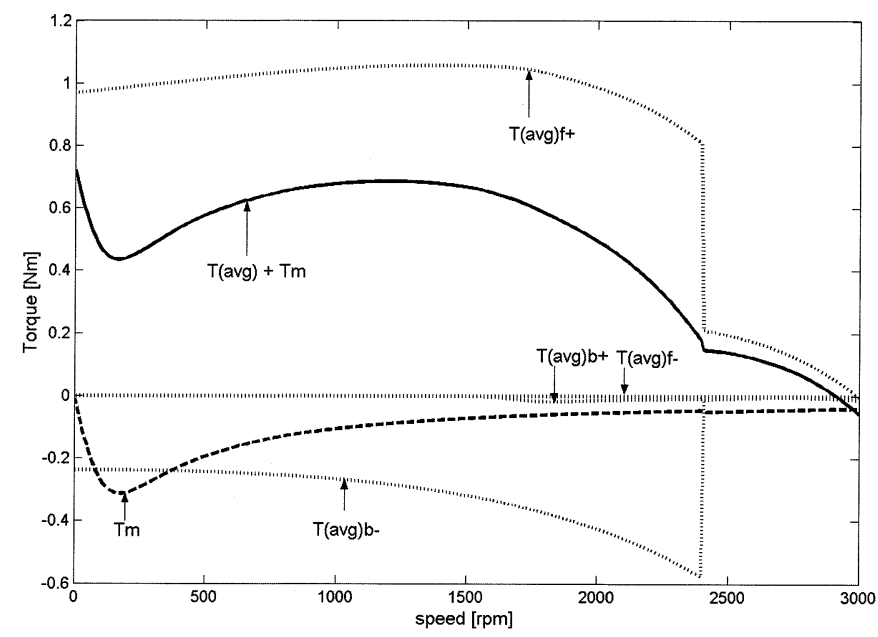

Fig. 7. Resultant torque components (cage and magnet braking torque) variation versus speed during starting operation-Motor A.

starting operation, for a wide range of capacitance values. The tested motors exhibit important torque oscillations at low speed. This phenomenon makes very difficult any measurement for locked-rotor or low-speed conditions.

Figs. 7-10 present the average torque components, in quasisteady-state analysis. The solid line represents the resultant average torque, while the dotted lines show the cage torque components and dashed line shows magnet braking torque. A comparison with the experimental results in Figs. 3-6 shows an overall good agreement for motors B and C, while for motor A the predictions are accurate for low and high speed (slip belongs to intervals $[0,0.3]$ and $[0.7,1])$. Figs. 11-14 show the pulsating torque components zero to peak amplitude. The solid lines represent the cage pulsating torque components, while the magnet pulsating torque components are illustrated using dashed lines. One can note the higher values for the unbalanced stator [(35) and (36)] and magnet (excitation) pulsating torque [(39) and (40)]. In Figs. 15-18, the dynamic torque and quasi-steadystate average resultant torque (solid line) and the envelope of the instantaneous torque are presented (dashed lines). The dynamic torque $\left(T_{\mathrm{dyn}}\right)$ simulation pattern follows that described in [1]. The minimum and maximum envelope trajectory $\left(T_{\text {env } \max }\right.$, $\left.T_{\text {env min }}\right)$ are obtained by superimposing the pulsating torque 


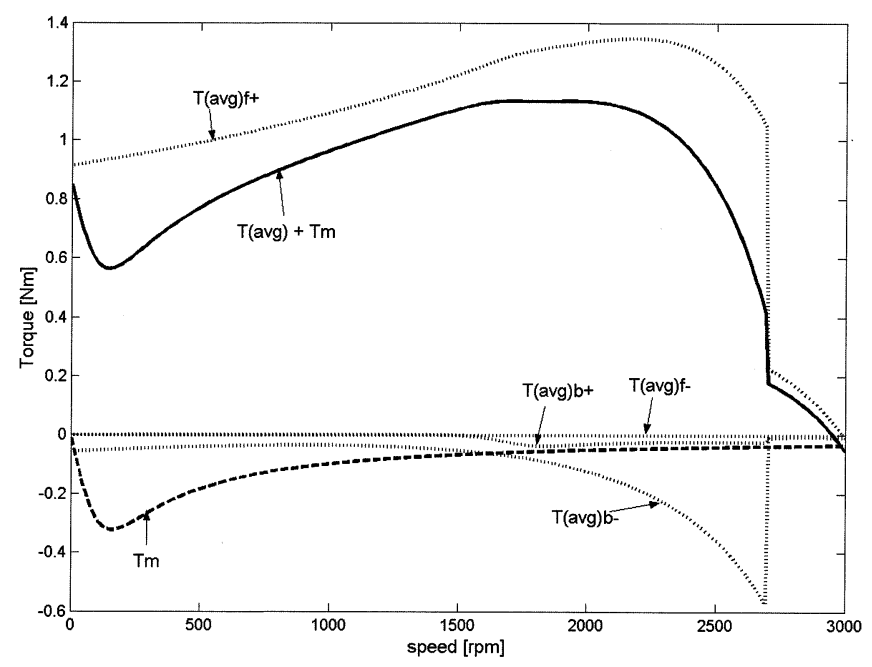

Fig. 8. Resultant torque components (cage and magnet braking torque) variation versus speed during starting operation-Motor B.

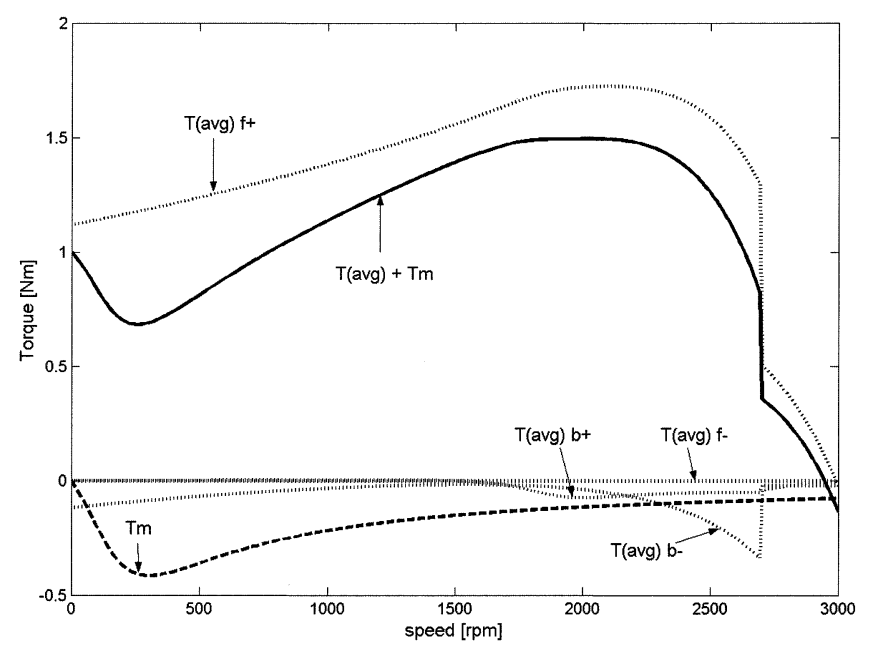

Fig. 9. Resultant torque components (cage and magnet braking torque) variation versus speed during starting operation-Motor C.

components effect over the average resultant torque. This approach neglects the mechanical pulsation due to rotor/load inertia and assumes that even though pulsating torque components vary with different frequencies, their global effect may be simulated by superposition. The slight difference between the quasi-steady-state torque and dynamic torque is due to the rotor inertia influence and the pulsating torque variation with frequency harmonics (Table I).

All simulations have been implemented neglecting saturation and core losses. However, the proposed model equations may include nonlinear effects such as core losses or saturation.

The equivalent circuit parameters defined in nomenclature have been either measured or computed with the use of SPEED software: PC-IMD v. 3.0, PC-BDC v. 6.0, and PC-FEA v. 5.0.

\section{TORQUE COMPONENTS CHARACTERISTICS}

For the average cage torque components, the main observations are as follows.

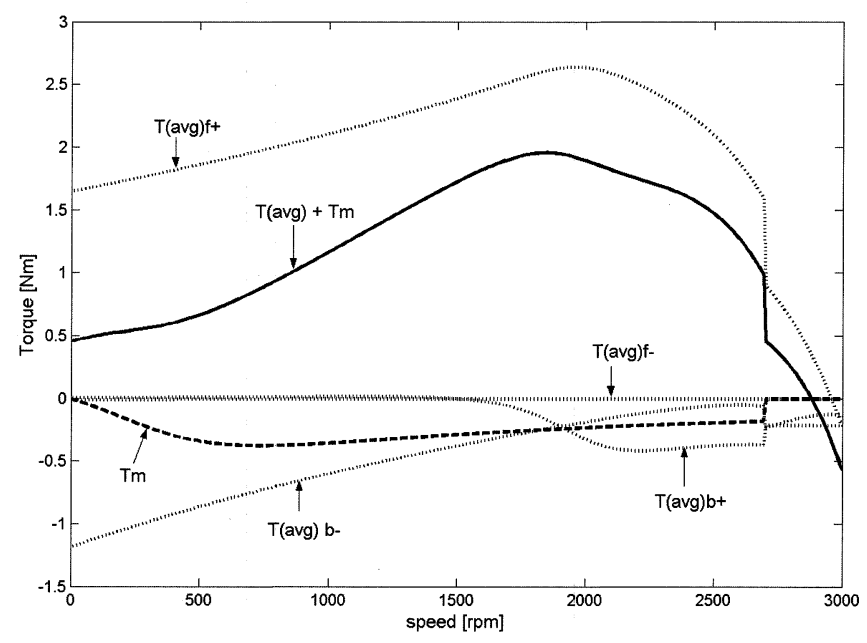

Fig. 10. Resultant torque components (cage and magnet braking torque) variation versus speed during starting operation-Motor D.

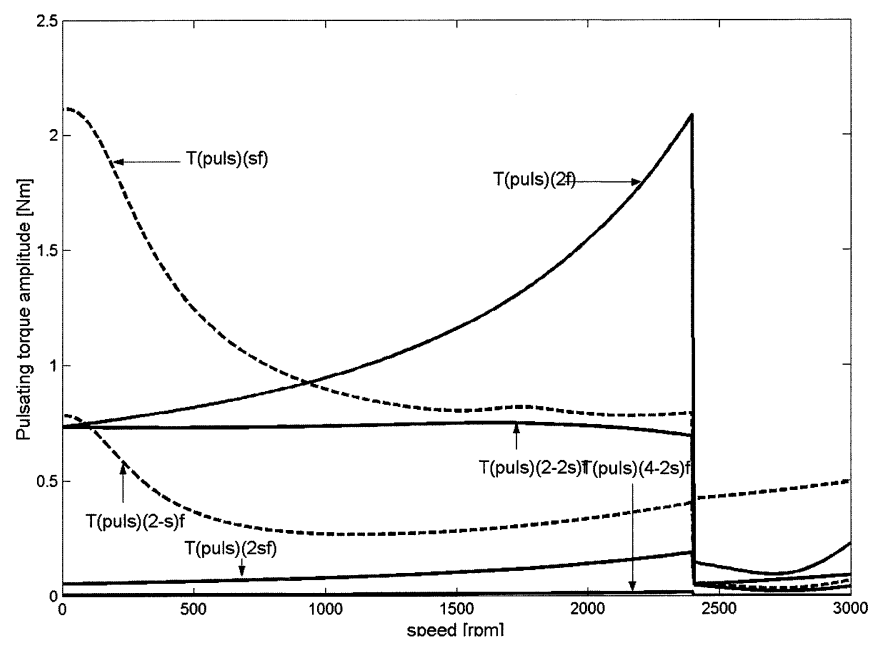

Fig. 11. Pulsating torque amplitude components variation versus speed during starting operation-Motor A.

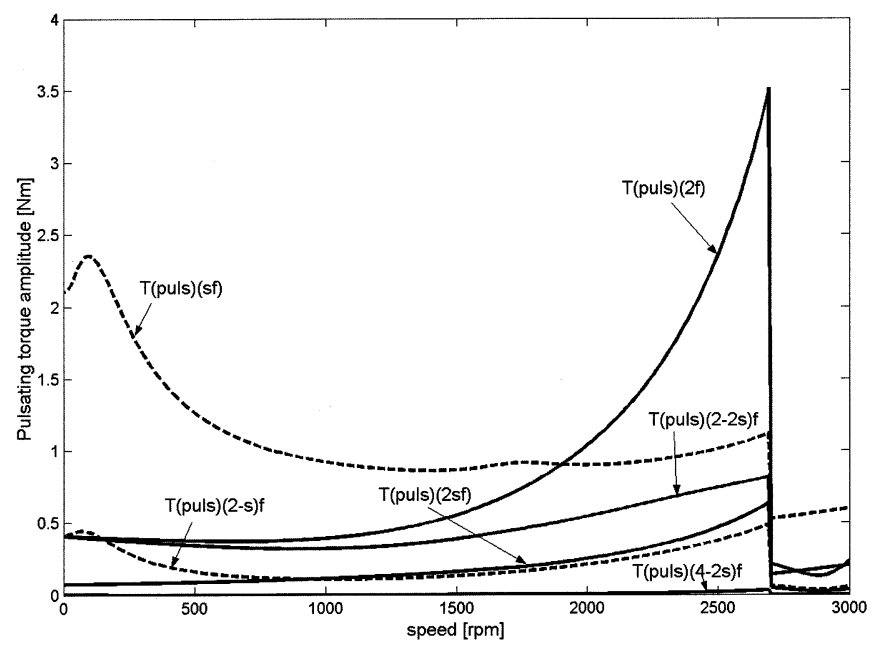

Fig. 12. Pulsating torque amplitude components variation versus speed during starting operation-Motor B. 


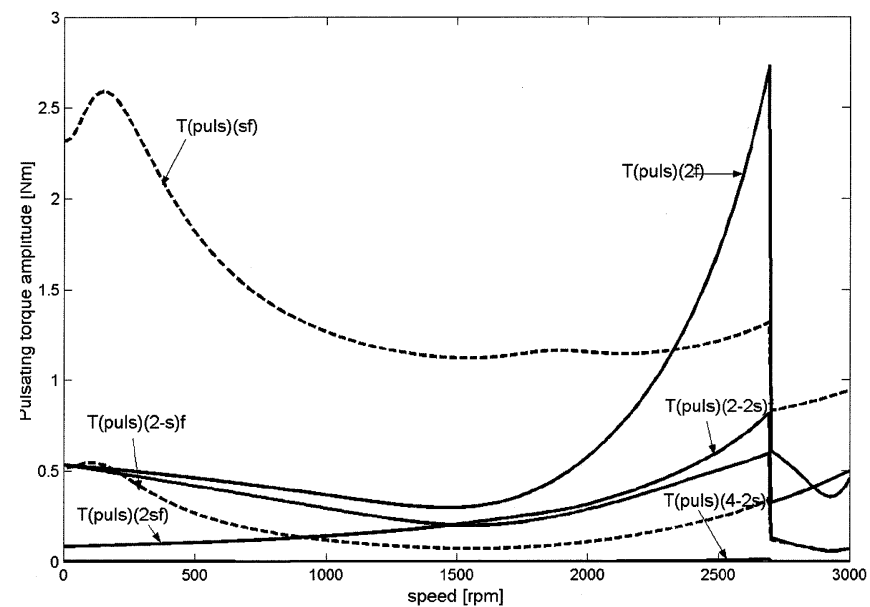

Fig. 13. Pulsating torque amplitude components variation versus speed during starting operation-Motor C.

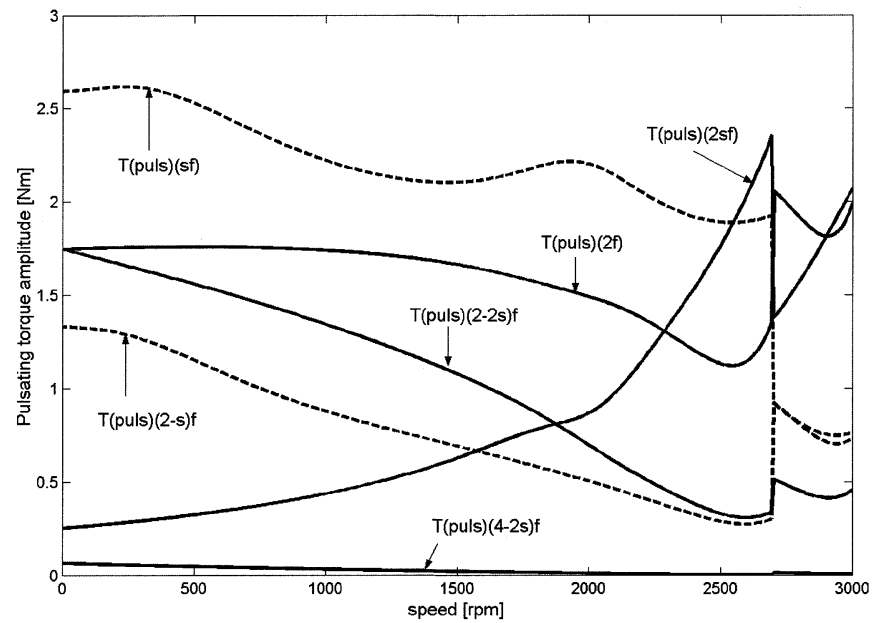

Fig. 14. Pulsating torque amplitude components variation versus speed during starting operation-Motor D.

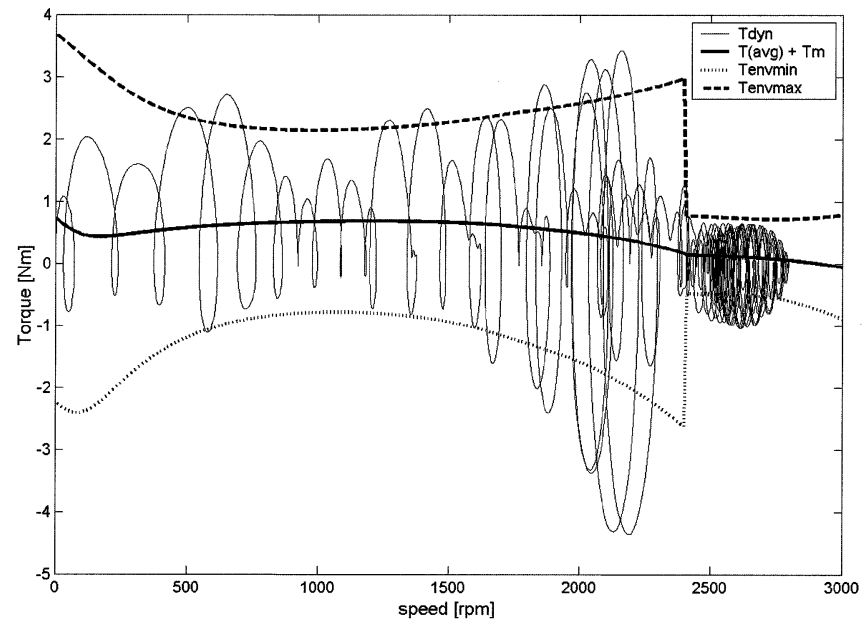

Fig. 15. Dynamic, resultant torque, and envelope with pulsating components variation versus speed during starting operation-Motor A.

1) The positive forward-sequence torque $\left(T_{(\mathrm{avg}) f+}\right)$ is the main component, which ensures good starting capabilities

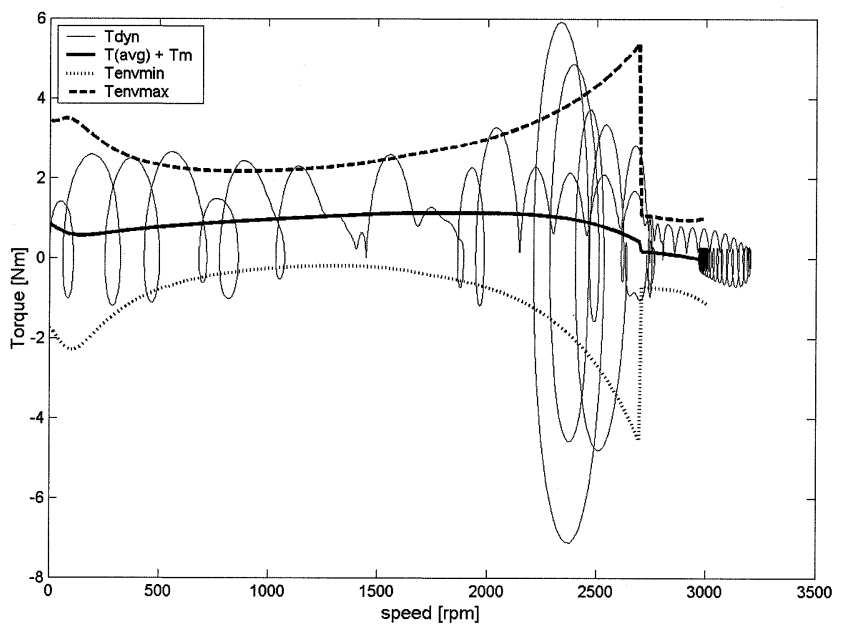

Fig. 16. Dynamic, resultant torque, and envelope with pulsating components variation versus speed during starting operation-Motor B.

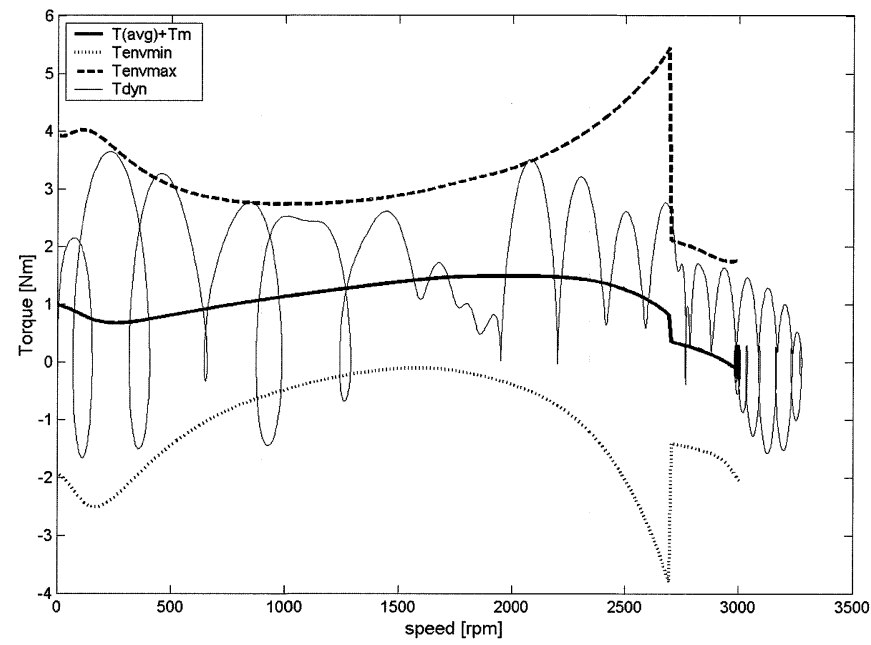

Fig. 17. Dynamic, resultant torque, and envelope with pulsating components variation versus speed during starting operation-Motor C.

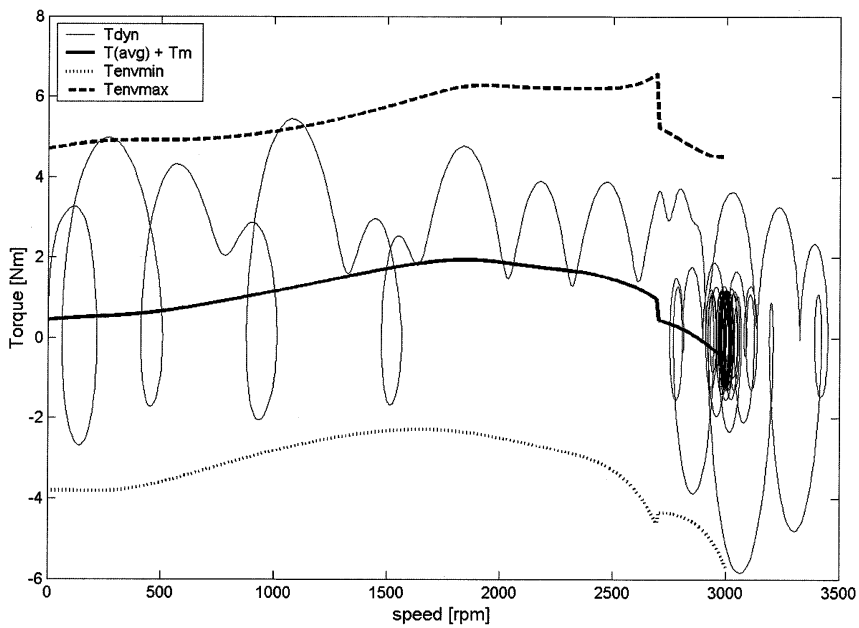

Fig. 18. Dynamic, resultant torque, and envelope with pulsating components variation versus speed during starting operation-Motor D.

for a single-phase PM motor. A higher starting torque condition requires a high-resistance rotor cage, but this 
feature will present the classical "dip" at half synchronous speed, in a similar way to the Goerges [5] phenomenon in induction motors with an unsymmetrical rotor. This "dip" can be minimized by using lower resistance rotor bars, or almost symmetrical cage rotors, i.e., $R_{r d} \approx R_{r q}$. The synchronization imposes the necessity of a high torque for low slip, which requests a low-resistance rotor bar. Therefore, an optimum value for the cage rotor resistance must be employed.

2) The positive backward-sequence torque $\left(T_{(\operatorname{avg}) b+}\right)$ which amplifies the half synchronous speed "dip," and the negative forward-sequence torque $\left(T_{(\operatorname{avg}) f_{-}}\right)$which always has negative values and diminishes the resultant cage torque, can be minimized by using a minimum admissible value for the stator resistance. However, this task is hard to achieve for small motors $\left(P_{n}<1 \mathrm{~kW}\right)$.

3) Obviously, the minimization of negative-sequence voltage amplitude toward zero (i.e., by using a correct choice for the run capacitor [1]), leads to the elimination of negative-sequence average torque components.

4) It is of interest that the developed air-gap cage torque at synchronous speed is not zero as in a symmetrical induction motor. The average cage torque of the asymmetrical PM machine at $s=0$ is always negative. This phenomenon is due to the positive backward and negative forward-sequence torques $\left(T_{(\operatorname{avg}) b+}, T_{(\operatorname{avg}) f-}\right)$. The only exception is when the saliency effect can be neglected $X_{d} \approx X_{q}$, and the stator currents are balanced (negative-sequence voltage $\underline{V}-=0$ ). This nonzero average cage torque at synchronous speed does not depend on the cage parameters (resistance or leakage reactance). It can be stated that this is the effect of the rotor saliency and the fact that the stator resistance cannot be neglected for fractional horsepower ac motors such as the analyzed motor.

For the magnet braking torque, the main observations are as follows.

1) The maximum amplitude of the magnet braking torque may be decreased by employing a suitable value for the stator windings shift angle $(\zeta)[10]$, or an over unit value for turns ratio $(\beta)$.

2) The corresponding speed for the maximum amplitude of the magnet braking torque is susceptible to occur at higher than half synchronous speed for a one-phase unsymmetrical LSPM motor.

3) For pure single-phase motors (split-phase), when only one stator winding is energized, the magnetic field created by excitation (PMs) transforms from a rotating field opposed to the rotating field created by stator flux into a pulsating field and the corresponding braking torque vanishes.

For the pulsating torque components, the main observations areas follows.

1) The asymmetries on both stator and rotor determine six important pulsating torque components for the run-up pe$\operatorname{riod}[2 s f, 2 f,(2-2 s) f,(4-2 s) f,(2-s) f, s f]$ and two components for the synchronous operation $[2 f, 4 f]$, compared to two and zero components, respectively, for the three-phase symmetrical motor case [2].

2) All six pulsating torque components for the run-up period can further be split into another two components, if the analysis is to be made from the stator point of view.

3) Even for a symmetrical rotor (i.e., $d-q$-axes parameters are identical), the pulsating excitation and unbalanced stator torque components will not disappear completely. The unsymmetrical stator pulsating torque components $(2 f$ and $(2-2 s) f)$ are always present for an unbalanced stator voltage system. The double-frequency pulsating torque component represents the main cause of pulsating for the single-phase LSPM motor. This component is characteristic for any one-phase ac motor: induction, synchronous reluctance, or synchronous PM.

4) The forward-sequence excitation pulsating component (39) is responsible for larger pulsations especially at low speed (slip $\cong 1$ ), while the negative-sequence excitation pulsating component (40) has a comparable value with the reluctance pulsating torque components [(35) and (36)].

5) The reluctance pulsating torque components [2sf and $(4-2 s) f]$ are entirely dependent on the machine parameters (resistances and reactances). The difference between rotor $d-q$ axis resistances and leakage reactances $\left(R_{r d} \neq R_{r q}, X_{l r d} \neq X_{l r q}\right)$ determines an increased pulsating "dip" torque around the half synchronous speed region. The difference between magnetization $d-q$ axis reactances $\left(X_{m d} \neq X_{m q}\right)$ determines an increased pulsating torque around the synchronous speed region.

6) The rotor asymmetry is responsible for the nonzero reluctance pulsating torque at standstill $(s=1)$, and the stator asymmetry is responsible for the nonzero unbalanced stator pulsating torque even at synchronous speed operation. For a single-phase PM motor, the proper selection of a capacitor to obtain a balanced stator voltage system will lead only to the minimization toward zero of the stator asymmetry effect. The rotor asymmetry effect cannot be eliminated.

\section{CONCLUSION}

The starting performance prediction for a line-start PM motor can be made using a quasi-steady-state analysis. The motor torque behavior during asynchronous operation can be calculated through the study of different torque components: cage torques, magnet braking torque, and pulsating torques. The deduced torque expressions may be extended for the general case of the $m$-phase ac motor, supplied with unbalanced stator voltage.

\section{REFERENCES}

[1] T. J. E. Miller, "Single-phase permanent magnet motor analysis," IEEE Trans. Ind. Applicat., vol. IA-21, pp. 651-658, May/June 1985.

[2] V. B. Honsinger, "Permanent magnet machine: Asynchronous operation," IEEE Trans. Power App. Syst., vol. PAS-99, pp. 1503-1509, July 1980. 
[3] B. Adkins and R. G. Harley, The General Theory of Alternating Current Machines. London, U.K.: Chapman \& Hall, 1975.

[4] I. Boldea, T. Dumitrescu, and S. Nasar, "Unified analysis of 1-phase AC motors having capacitors in auxiliary windings," IEEE Trans. Energy Conversion, vol. 14, pp. 577-582, Sept. 1999.

[5] H. L. Gabarino and E. T. B. Gross, "The Goerges phenomenon-Induction motors with unbalanced rotor impedances," AIEE Trans., vol. 69, pp. $1569-1575,1950$.

[6] S. Williamson and A. M. Knight, "Performance of skewed single-phase line-start permanent magnet motors," IEEE Trans. Ind. Applicat., vol. 35, pp. 577-582, May/June 1999.

[7] C. M. Stephens, G. B. Kliman, and J. Boyd, "A line-start permanent magnet motor with gentle starting behavior," in Conf. Rec. IEEE-IAS Аnnu. Meeting, vol. 1, 1998, pp. 371-379.

[8] M. A. Rahman and A. M. Osheiba, "Performance of large line-start permanent magnet synchronous motors," IEEE Trans. Energy Conversion, vol. 5, pp. 211-217, Mar. 1990.

[9] R. Carlson, N. Sadowski, S. R. Arruda, C. A. da Silva, and L. Von Dokonal, "Single-phase line-started permanent magnet motor analysis using finite element method," in Conf. Rec. IEEE-IAS Annu. Meeting, vol. 1, 1994, pp. 227-233.

[10] M. Popescu, T. Jokinen, E. Demeter, and V. Navrapescu, "Modeling and analysis of a two-phase induction machine with nonorthogonal stator windings," in Conf. Rec. IEEE IEMDC'99, Seattle, WA, May 1999, pp. 389-391.

[11] T. J. E. Miller, "Synchronization of line-start permanent magnet motors," IEEE Trans. Power App. Syst., vol. 103, pp. 1822-1828, July 1984.

[12] C. Concordia, Synchronous Machines. New York: Wiley, 1951.

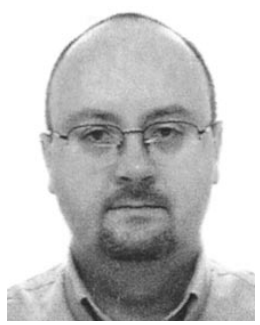

Mircea Popescu (S'98-M'99) was born in Bucharest, Romania, in 1959. He received the B.Sc. degree in statistics and economics from the Academy of Economical Studies, Bucharest, Romania, in 1992, and the M.Eng. and Ph.D. degrees in electrical engineering from the University "Politehnica" Bucharest, Bucharest, Romania, in 1984 and 1999, respectively.

From 1984 to 1986, he was involved in de drives design and quality testing at "Electrothenica" S.A. Bucharest. From 1986 to 1997, he worked in industrial research and development at the Research Institute for Electrical Machines (ICPE-ME), Bucharest, Romania, as a Project Manager. From 1991 to 1997, he cooperated as a Visiting Assistant Professor with the Electrical Engineering Faculty, Electrical Drives and Machines Department, University "Politehnica" Bucharest. From 1997 to 2000, he was a Research Scientist with the Electromechanics Laboratory, Helsinki University of Technology, Espoo, Finland. He is currently with the SPEED Laboratory, Glasgow University, Glasgow, U.K., as a Research Associate.

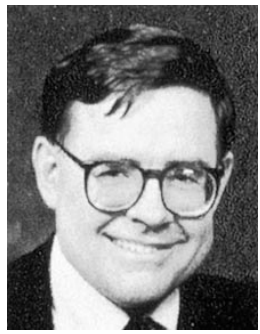

T. J. E. Miller (M'74-SM'82-F'96) is a native of Wigan, U.K. He received the B.Sc. degree from the University of Glasgow, Glasgow, U.K., and the Ph.D. degree from the University of Leeds, Leeds, U.K

$\mathrm{He}$ is Professor of Electrical Power Engineering and founder and Director of the SPEED Consortium at the University of Glasgow, Glasgow, U.K. He is the author of over 100 publications in the fields of motors, drives, power systems, and power electronics, including seven books. From 1979 to 1986, he was an Electrical Engineer and Program Manager at GE Research and Development, Schenectady, NY, and his industrial experience includes periods with GEC (UK), British Gas, International Research and Development, and a student apprenticeship with Tube Investments Ltd.

Prof. Miller is a Fellow of the Institution of Electrical Engineers, U.K.

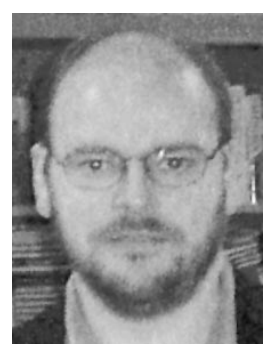

Malcolm I. McGilp was born in Helensburgh, U.K., in 1965. He received the B.Eng. (Hons.) degree in electronic systems and microcomputer engineering from the University of Glasgow, Glasgow, U.K., in 1987.

Since graduating, he has been with the SPEED Laboratory, University of Glasgow, first as a Research Assistant from 1987 to 1996 and as a Research Associate since then. He is responsible for the software architecture of the SPEED motor design software and has developed the interface and user facilities which allow it to be easy to learn and integrate with other PC-based software.

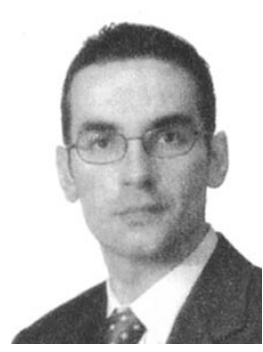

Giovanni Strappazzon graduated from the Faculty of Electrical Engineering, Padua University, Padua, Italy, in 1998, on the basis of a dissertation about analysis of small induction motors for the optimization in the design of electrical motors.

He worked shortly for a factory that makes small synchronous motors mainly for aquarium pumps. Since the beginning of 2001, he has been a Researcher on innovative motors for Electrolux Compressors, Pordenone, Italy.

Mr. Strappazzon won an award as a Researcher in the Department of Electrical Engineering, Padua

University, in 1999.

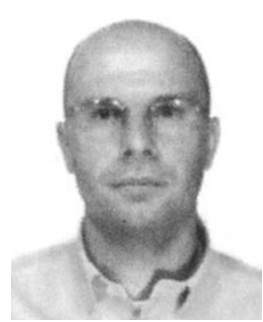

Nicola Trivillin was born in Pordenone, Italy, in 1970. He received the "Laurea" degree in electrical engineering from Padua University, Padua, Italy, in 1995, with a thesis on finite-element analysis of a single-phase induction motor with auxiliary phase.

He joined the R\&D Department of Electrolux Compressors, Pordenone, Italy, as an Electric Motor Specialist, and is currently Manager of the Electrical Competence Center.

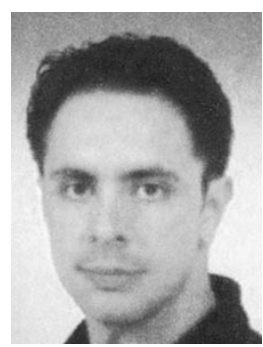

Roberto Santarossa was born in Pordenone, Italy, in 1969. He received the degree in electrical engineering from the University of Padua, Padua, Italy, in 1996, with a thesis about voltage stability of a large electric power system.

Since 1997, he has been with Electrolux Compressors, Pordenone, Italy, where he is currently an Electric Motor Designer, dealing with design and development of fractional horsepower motors. 